\title{
Aspectos gerais sobre adesivos para madeira
}

\section{General aspects on stickers to wood}

Aspectos generales sobre adhesivos para madera

Zaíra Morais dos Santos Hurtado de Mendoza ${ }^{1}$

Pedro Hurtado de Mendoza Borges ${ }^{2}$

Anatálya dos Santos Ribeiro ${ }^{3}$

Francisco Batista Fernandes ${ }^{4}$

${ }^{1}$ Professora, Doutora, Faculdade de Engenharia Florestal (FENF), Departamento de Engenharia Florestal, Área de Tecnologia e Utilização de Produtos Florestais, Universidade Federal de Mato Grosso (UFMT), Cuiabá, Mato Grosso. E-mail: zaira@ufmt.br

2 Professor, Doutor, Faculdade de Agronomia e Zootecnia, (FAAZ), Departamento de Solos e Engenharia Rural, Área de Construções Rurais e Máquinas Agrícolas, Universidade Federal de Mato Grosso (UFMT), Cuiabá, Mato Grosso. E-mail:pborges@ufmt.br

3 Engenheira Florestal, Mestre, Faculdade de Engenharia Florestal (FENF), Área de Silvicultura, Universidade Federal de Mato Grosso (UFMT). E-mail: anatalya_ribeiro@hotmail.com

${ }^{4}$ Engenheiro Florestal, Graduado, Faculdade de Engenharia Florestal (FENF), Universidade Federal de Mato Grosso (UFMT).

E-mail: fb.fernandes@outlook.com 
Resumo: A colagem da madeira é uma técnica antiga que ainda se destaca devido à escassez de matéria-prima. Para que se obtenha êxito na colagem, é necessário estudar e conhecer bem as características de cada adesivo utilizado no processo, visando a seu melhor aproveitamento, ao aumento de qualidade da peça e à redução de custos. Este trabalho descreve os principais adesivos empregados na colagem de madeira, indicando suas principais características e ressaltando sua importância na área de industrialização. Os adesivos podem ser classificados em naturais ou sintéticos, sendo este último grupo dividido em termoplásticos e termofixos. As propriedades dos adesivos que mais influenciam na colagem de madeira são pH, viscosidade, tempo de trabalho e teor de substâncias sólidas. Os conceitos fundamentais em que se baseiam o processo de colagem são adesão, adesivo e aderente.

Palavras-chave: resina; colagem; propriedades; usos.

\begin{abstract}
The wood collage is an old technique that still stands out due to shortage of raw material. In order to achieve success in bonding, it is necessary to study and know well the characteristics of the adhesive used in the process to its best use, the increase part quality and cost reduction. This paper describes the main adhesives used in wood glue, indicating its main features and highlighting its importance in the manufacturing area. The adhesives can be classified into natural or synthetic, and the last one divided into thermoplastic and thermoset. The adhesive properties more influents in wood gluing are $\mathrm{pH}$, viscosity, working time and content of solid substances. The fundamental concept on which to base the bonding process are adhesion, adhesive and adherent.
\end{abstract}

Key words: resin; collage; properties; uses.

Resumen: La collage de madera es una técnica antigua que aún se destaca debido a la escasez de materia prima. Con el fin de lograr el éxito en la adhesión, es necesario estudiar y conocer bien las características del pegamento utilizado en el proceso para su mejor uso, elevar la calidad de las piezas y reducir los costos. En este trabajo se describen los principales adhesivos empleados para pegar madera, indicando sus principales características y destacando su importancia en el área de fabricación. Los adhesivos se pueden clasificar en natural o sintético, siendo que este último grupo se divide en termoplásticos y termoestables. Las propiedades de los adhesivos que más influyen en la cola de madera son el pH, la viscosidad, el tiempo de trabajo y el contenido de sustancias sólidas. Los conceptos fundamentales sobre los cuales se fundamenta el proceso de unión son adhesión, adhesivo y adherente.

Palabras clave: resina; unión; propiedades; usos. 


\section{INTRODUÇÃO}

Atualmente, as restrições impostas pela legislação impedem que a crescente demanda por matéria-prima florestal seja atendida apenas por florestas nativas, e a expansão da área ocupada por florestas plantadas ainda não é capaz de atender tal demanda. Diante desse cenário, a colagem de madeira para obtenção de peças maiores, se destaca como uma alternativa para minimizar o consumo de madeiras na forma de toras.

A colagem da madeira é uma técnica muito antiga, mas também muito complexa, pois envolve diversas variáveis, que vão desde as características da madeira utilizada até as propriedades do adesivo. A qualidade dessa colagem é verificada pela linha de cola, a qual serve para predizer o desempenho do adesivo, quando submetido à aplicação de esforços. A reconstrução da madeira é um processo interessante para a indústria, pois as características estruturais podem ser facilmente manejadas de acordo com a finalidade da peça. Para tanto, é necessário estudar e conhecer bem as características de cada adesivo utilizado no processo de colagem, visando a seu melhor aproveitamento, ao aumento de qualidade da peça e à redução de custos. Cada adesivo possui uma propriedade própria, que o faz destacar-se em relação aos outros.

O objetivo deste trabalho foi descrever os aspectos gerais sobre os principais adesivos empregados na colagem de madeira, ressaltando sua importância na área de industrialização da madeira.

\section{MATERIAL E MÉTODOS}

O estudo foi realizado na forma de revisão de literatura, utilizando-se como referências revistas acadêmicas, artigos científicos, livros e ferramentas de busca da internet. 


\section{REVISÃO DE LITERATURA}

\subsection{Contexto histórico}

O uso de adesivos pela humanidade é muito antigo, e existem registros desde 3.000 anos antes de Cristo. Os egípcios já usavam uma goma arábica retirada de essências florestais e uma cola feita com pasta de farinha na fabricação dos primeiros papiros de lâminas finas, justapostas e coladas (AZEVEDO, 2009). Iwakiri (2005) descreve lama e argila, albumina (sangue), caseína (leite), glutina (couro, pele, ossos), como sendo as primeiras substâncias com propriedades adesivas de que se têm conhecimento.

Segundo Campos e Lahr (2004), o estudo dos adesivos pouco evoluiu até o início do século XX. A maior parte dos adesivos utilizados até a primeira guerra mundial era à base de proteína animal. Após esse período, começaram a surgir novos adesivos mais resistentes à água e que podem ser aplicados a temperatura ambiente. Esses adesivos são empregados até hoje, em vários países, na colagem de peças estruturais de madeira para uso interno.

Na década de 1930, os adesivos sintéticos causaram uma verdadeira revolução na produção e no design de móveis. Em 1929, foi criado o fenol-formaldeído, o primeiro adesivo sintético; em 1931, surgiu o adesivo à base de ureia-formaldeído; em 1939, o adesivo de melamina-formaldeído; e, em 1943, o adesivo de resorcina-formaldeído (IWAKIRI, 2005).

Durante a Segunda Guerra Mundial, novos adesivos foram desenvolvidos como o resorcinol-formaldeído, de maior custo, porém mais resistente à água. Nessa mesma época, foram produzidos também os primeiros adesivos poliuretanos criados por Otto Bayer em 1937, na Alemanha (AZEVEDO, 2009).

Nos anos 50, surgiu o adesivo termoplástico de PVA (acetato de polivinila), apresentando como vantagens o baixo custo, cura em tem- 
peratura ambiente e empregado para usos interiores (IWAKIRI, 2005). Azevedo (2009) ressalta que a grande parte dos adesivos utilizados na colagem de madeiras é sintetizada a partir de solventes orgânicos. Esses solventes têm características cancerígenas e mutagênicas.

As autoridades ligadas à saúde estão bastante preocupadas e tendem a exigir a substituição por adesivos menos tóxicos. Como a maioria das matérias-primas para a fabricação de adesivos são oriundas de fontes não renováveis e apresentam alto custo, outras alternativas têm sido estudadas. O tanino vem sendo uma opção natural como fonte de adesivo. Ele é um polifenol que pode ser obtido de vários materiais renováveis, como por exemplo, da casca de acácia negra (Acácia mearnsii De Wild), do Pinus radiata e da madeira do cerne do quebracho (Schinopsis sp.) (TEODORO; LELIS, 2005). Em contrapartida, César (2011) ressalta que os uso de taninos tem algumas limitações. Esses compostos podem conter algumas substâncias fenólicas ativas, traços de aminoácidos, além de açúcares e gomas com alto peso molecular. A presença de glucose pode diminuir a qualidade da colagem. Ainda segundo a autora, os adesivos à base de taninos de eucalipto e angico-vermelho possuem viscosidade com valores elevados e tempo de trabalho curto, o que pode gerar problemas para a indústria.

César (2011) destaca que os principais adesivos utilizados na fabricação de painéis de madeira são o fenol-formaldeído, o resorcinolformaldeído, a ureia-formaldeído e melanina-formaldeído. De acordo com Campos e Larh (2004), esses quatro adesivos respondem por $90 \%$ de todos os adesivos utilizados na fabricação de painéis de madeira reconstituída.

Carneiro et al. (2012) relatam que, com a crise do petróleo nos anos 1970 e com o aquecimento global, que tem se agravado muito nas últimas décadas, adesivos com compostos orgânicos voláteis tendem a ser substituídos por alternativas ecologicamente corretas. Os poliuretanos obtidos através do óleo de mamona e os adesivos 
de silicatos são vistos como solução para esse problema (MENDOZA, 2010).

\subsection{Generalidades sobre os adesivos}

Adesivo é uma substância com propriedades aderentes capaz de unir outros materiais em sua superfície (IWAKIRI, 2005). Eles podem ser naturais ou sintéticos. Os adesivos naturais podem ter origem animal, como a albumina e a caseína ou vegetal, tal como a batata e o látex (CESAR, 2011). Carneiro (2010) relata que os adesivos naturais podem ser obtidos de proteínas animais e vegetais, celulose, tanino, amidos, gomas naturais, entre outros. Outro adesivo natural, já bastante utilizado na área de papel, é o silicato de sódio. Segundo Carneiro (2010), os adesivos à base de silicatos são classificados como compostos inorgânicos. Esses adesivos produzem ligações mecânicas com alta resistência, e sua ligação ocorre pela desidratação do solvente do adesivo. Mendoza (2010) classifica esse tipo de adesivo como não prejudicial ao meio ambiente e o indica como uma opção interessante para a produção de compósito de madeira.

Os adesivos sintéticos são fabricados pelo homem, com características semelhantes aos naturais, porém adaptados para cada tipo de uso e mais resistentes à água (ECKELMAN, 1997 apud CESAR, 2011). Eles podem ser separados em termofixos e termoplásticos.

Os adesivos termofixos sofrem reações químicas com ou sem calor e passam a ter caraterísticas de insolubilidade de forma irreversível. Já os adesivos termoplásticos resistem apenas a mudanças físicas, sofrendo alterações com a ação do calor ou solventes, entre eles podemos citar o PVA (Acetato de Polivinila) e o PVC (Policloreto de Vinila) (PIZZI; MITTAL, 1994 apud BIANCHE, 2014). Os principais adesivos sintéticos termofixos ou termoendurecedores são a ureia-formaldeído, o fenol-formaldeído, a melanina-formaldeído e o resorcinol-formaldeído. 
Juntos eles correspondem a 90\% de todos os adesivos utilizados em processos de colagem de madeira (CAMPOS; LARH, 2004).

A ureia-formaldeído possui coloração branca leitosa, teor de sólidos entre 64 a 66\%, pH entre 7,4 a 9,0, viscosidade entre 400 a $1000 \mathrm{cp}$, temperatura de cura entre $90^{\circ}$ a $120^{\circ} \mathrm{C}$ e pode ser armazenada por 3 meses em estado líquido e até por um ano em sua fase de pó. É mais indicada para peças de madeira que são protegidas da umidade, como móveis e peças de uso interior (IWAKIRI, 2005).

Os adesivos fenol-formaldeído apresentam coloração marrom avermelhado, teor de sólidos ente 48 a 51\%, pH entre 11 a 13, viscosidade entre 300 a $600 \mathrm{cp}$, temperatura de cura entre $130^{\circ}$ a $150^{\circ} \mathrm{C} \mathrm{e}$ podem ser armazenados por 4 a 5 meses em temperatura ambiente. São mais resistentes à água do que a ureia-formaldeído, sendo, por isso, até 2,5 vezes mais caros (EMERSON, 2010).

De acordo com Iwakiri (2005), a melanina-formaldeído é uma resina com qualidade intermediária entre ureia-formaldeído e fenolformaldeído. Tem a vantagem de ser mais resistente que a ureiaformaldeído, e a cura mais rápida que a fenol-formaldeído. Possui coloração branca leitosa, teor de sólidos ente 65 a 67\%, pH entre 7,5 a 9,0, viscosidade entre 150 a $210 \mathrm{cp}$, temperatura de cura entre $65^{\circ} \mathrm{a}$ $130^{\circ} \mathrm{C}$, podendo ser armazenada, por até um mês, em estado líquido e, até um ano, em forma de pó. A resorcina-formaldeído possui cura a frio, com o uso de um catalizador, é muito utilizada na construção naval e na aviação devido à sua alta resistência à umidade. Possui um custo bem mais elevado em relação às resinas citadas anteriormente. Tem coloração marrom, teor de sólidos ente 53 a 55\%, pH entre 6,9 a 7,5, viscosidade entre 500 a 800cp e pode ser armazenada por um ano em temperatura ambiente (IWAKIRI, 2005).

Segundo Lima (2006), o adesivo termoplástico mais importante para a colagem da madeira é o PVA. Esse adesivo é uma emulsão de acetato de polivinila, utilizado para fabricação de móveis, colagem de 
lâminas e em serviços de marcenaria e carpintaria em geral. Conforme Iwakiri (2005), as resinas PVA, por serem à base de água, apresentam vantagens como manuseio simples e seguro, ausência de odor, não são inflamáveis, possuem baixo custo se comparadas a outras resinas comerciais, possuem secagem rápida sob condições adequadas, são de fácil limpeza e possuem boa estabilidade à estocagem. Ainda segundo o mesmo autor, a sua cura acontece em temperatura ambiente e é restrito ao uso interior, em virtude da baixa resistência à umidade.

Outra aplicação dos adesivos termoplásticos é na produção de compósitos plástico/madeira, que são produtos obtidos a partir de uma matriz, contínua ou descontínua, de resina termoplástica reforçada com partículas de madeira (MACIEL et al., 2004).

\subsection{Principais propriedades dos adesivos}

Almeida et al. (2010) destacam que as principais propriedades dos adesivos que influenciam diretamente na colagem da madeira são: viscosidade, tempo de trabalho, teor de substâncias solidas e pH.

\subsubsection{Viscosidade}

A viscosidade é a propriedade dos fluidos que corresponde ao seu transporte. Quanto maior a viscosidade, menor a velocidade com que o fluido se movimenta (AZEVEDO, 2009). Stella (2009) define viscosidade como sendo a resistência ao fluxo livre que um substância líquida pode apresentar entre as camadas de uma matéria, ou um valor que demonstre existência de atrito entre as moléculas de um fluido, e que se manifesta pelo escoamento.

Almeida (2009) menciona que a fluidez de um líquido está relacionada com sua viscosidade e que essa propriedade pode determinar o tempo de validade de um adesivo. Para a colagem da madeira, são desejados valores medianos de viscosidade, pois adesivos 
com viscosidade muito alta tendem a distribuir-se de forma irregular na madeira, gerando uma linha de cola espessa por causa da difícil penetração do adesivo na madeira. Todavia, quando a viscosidade é muito baixa, ocorre uma maior penetração na estrutura da madeira, gerando assim uma linha de cola faminta.

De acordo com César (2011), a determinação da viscosidade é realizada pelo método do copo graduado "cup-method" ou "Ford", em que ocorre a medição do tempo de passagem do líquido pelo orifício do copo, sendo a viscosidade calculada em Centipoase (cP).

\subsubsection{Tempo de trabalho}

Stella (2009) descreve o tempo de trabalho como sendo o tempo de vida útil do adesivo, que se estende desde a sua preparação até a fase de gel, em que este atinge a sua máxima rigidez. O tempo de trabalho dos adesivos não deve ser muito longo, pois aumentaria o tempo de prensagem. Contudo, Carneiro (2006) menciona que um tempo de trabalho muito curto dificulta a aplicação e o espalhamento do adesivo na madeira, devido à sua rápida polimerização, provocando queda na resistência da linha de cola.

\subsubsection{Teor de substâncias sólidas}

Mendoza (2010) define o teor de sólidos como sendo a quantidade de sólidos resinosos contido no adesivo. O adesivo é composto de materiais sólidos e líquidos voláteis. Com evaporação dos componentes líquidos, ocorre a "cura" ou polimerização do adesivo formando a linha de cola, que é responsável pela ligação entre os substratos e transferência de tensões geradas no sistema madeira-linha de colamadeira. Essa propriedade é de grande importância na colagem de madeiras, pois é através dela que se sabe quanto de adesivo efetivamente forma a linha de cola. 
O teor de sólidos é uma propriedade muito importante no que se refere à qualidade da colagem. Esse material forma a linha de cola propriamente dita, uma vez que a água e outros materiais voláteis evaporam durante a prensagem. Sua quantidade pode prejudicar a colagem, tanto pela escassez de material sólido na linha de cola, tanto pelo excesso de materiais que podem causar deformações na peça colada (ALMEIDA, 2009). Com a solidificação do adesivo, os sólidos adquirem novas propriedades e ocorre a coesão. São eles que conferem resistência e durabilidade a peça colada (IWAKIRI, 2005). O teor de substâncias sólidas é obtido secando-se 1 grama do adesivo em estufa à temperatura de $103 \pm 3^{\circ} \mathrm{C}$, por 3 horas, e deixando esfriar em dessecador, por 15 min. Após esse tempo, é realizada novamente a pesagem. O teor de sólidos percentual pode ser calculado pela diferença entre a massa inicial e final dividida pela massa inicial (CÉSAR, 2011).

\subsubsection{Potencial Hidrogeniônico $(\mathrm{pH})$}

O pH de uma solução aquosa é caracterizado pela concentração de íons dissociados de $\mathrm{H}^{+}$e $\mathrm{OH}^{-}$. Para se determinar o seu valor, é necessário um aparelho chamado pHmetro ou potenciômetro.

Stella (2009) considera importante a influência do pH, tanto na madeira, quanto na resina. Ainda segundo a autora, resina com valores abaixo de 2,5 e acima de 11 podem degradar a fibra da madeira. Marra (1992 apud IWAKIRI, 2005) afirma que pH com valores muito baixos formam espuma em excesso, o que dificulta a aplicação do adesivo. A resina ureia-formaldeído possui cura em meio ácido, logo, madeiras com pH alto tornam o processo de cura do adesivo mais rápido, podendo inclusive provocar pré-cura da resina durante a prensagem dos painéis. Já a resina fenol-formaldeído tem a cura facilitada em meio alcalino (STELLA, 2009; ALMEIDA, 2009). Iwakari et al. (2000) reforçam que madeiras com pH muito ácido podem causar 
a pré-cura da resina ureia-formaldeído durante a fase de fechamento da prensa, prejudicando as propriedades finais da chapa. Entretanto, na colagem com resina fenol-formaldeído para produção de chapas estruturais, um baixo $\mathrm{pH}$ da madeira pode retardar a cura da resina (KELLY, 1977 apud IWAKARI, 2005).

\subsection{COLAGEM}

De acordo com a Associação Brasileira da Indústria de Madeira Processada Mecanicamente (ABIMCI, 2003), o processo de colagem envolve três conceitos fundamentais, a saber:

- Adesão: é um fenômeno físico e químico que provê um mecanismo de interação entre superfícies sólidas.

- Adesivo: é um material com propriedades aderentes, isto é, uma substância capaz de manter unidos outros materiais em suas superfícies.

- Aderente: termo usado para sólidos (madeira) unidos por adesivos.

Mendoza (2010) relata que a análise de uma ligação adesiva deve ser feita considerando-se o desempenho do sistema adesivo/aderente. Segundo Jesus (2000), a solubilidade do adesivo no aderente, a rugosidade do aderente, a penetração do adesivo no aderente, a fluidez e viscosidade do adesivo, a espessura da linha de cola e a pressão aplicada, têm influência direta na colagem da madeira. O maior grau de molhagem permite um maior contato entre adesivo e aderente, resultando em uma ligação mais resistente. A rugosidade da superfície do aderente pode proporcionar maior eficiência nas ligações, por apresentar maior área de contato do adesivo com o aderente.

Azevedo (2009) relata que o processo de adesão pode ser explicado por três teorias, sendo elas a teoria da adesão mecânica, da difusão de polímeros e da adesão química. Na teoria da adesão mecânica, uma boa adesão só ocorre quando o adesivo penetra em 
fendas, ou qualquer outra irregularidade da superfície da madeira e travando mecanicamente a peça. Em relação à madeira, o adesivo líquido, devido à sua fluidez, penetra através dos poros ocorrendo, posteriormente, a solidificação, com a formação de "ganchos" fortemente presos entre os substratos. Entretanto essa teoria não explica a adesão de materiais não porosos e também de madeiras tropicais muito densas, coladas com adesivos não solúveis em água. Na teoria da difusão dos polímeros, a adesão ocorre por meio da difusão de segmentos de polímeros situados em nível molecular através da interface que permite uma absorção gradual. Esse mecanismo pressupõe que correntes moleculares ou elos de correntes são suficientemente móveis e mutuamente solúveis. Os problemas de adesão, que ocorrem nos processos de penetração-solidificação, estão relacionados ao tempo de contato, temperatura e peso molecular dos polímeros, o que também afeta na resistência de linha de cola. De acordo com a teoria da adesão química, a adesão ocorre por meio de ligações primárias iônicas ou covalentes, ou por forças intermoleculares secundárias. A reação química produz uma ligação muito forte, em que os materiais colados não podem ser separados sem danificar os materiais já ligados. Os termos primário e secundário referem-se à resistência relativa ou energia de colagem de cada tipo de interação.

Vital et al. (2006) defendem que existem várias teorias que explicam o processo de adesão, porém nenhuma delas é capaz de explicar o processo como um todo. Os autores acreditam que a combinação entre elas é o que mais se aproxima da realidade.

As interações que ocorrem na região entre duas peças de madeira e o ambiente ali criado, no qual o adesivo realiza as ações de movimento, abrangem vários princípios e podem ser caracterizadas por nove elos numa cadeia, na qual cada elo é responsável por uma ação particular do adesivo, conforme descrito na Figura 1 (IWARIKI, 2005). De acordo com a figura 1, o "elo 1" corresponde ao filme do 
adesivo, os "elos 2 e 3" correspondem à camada de ligação intra-adesivo, os "elos 4 e 5" correspondem à interface adesivo/aderente, os "elos 6 e 7" correspondem à sub-superfície da madeira e os "elos 8 e 9" correspondem à madeira.

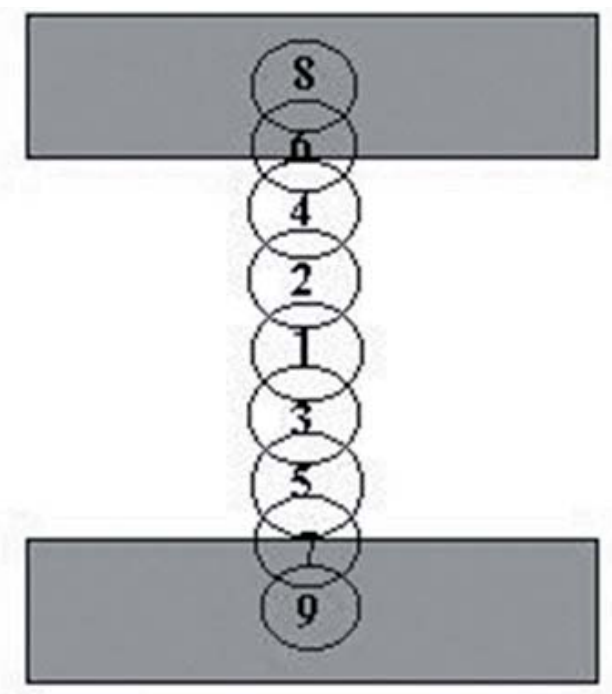

Figura 1 - Elos de conexão entre adesivo e substrato Fonte: Iwakiri (2005).

O processo de colagem de madeiras se inicia com a aplicação do adesivo sobre a superfície do substrato, em que ocorrem várias fases de movimento do adesivo até que ele se solidifique, formando ganchos ou pontos de ancoragem entre duas peças coladas. O grau de adesão depende da intensidade adesiva de cada elo. Iwakiri (2005) descreve que, após o contato inicial líquido-sólido, duas forças entram em ação: a força de coesão do líquido que tenta manter a sua forma esférica, correspondente ao estado de mínima energia superficial livre e a força de adesão entre líquido e sólido, em função da tensão superficial, que tenta estender a gota na superfície do material que está sendo colado. 
Essa competição entre as duas forças leva a diferentes níveis de umectação do substrato pelo líquido e, em função da magnitude das respectivas forças, pode resultar em três situações: umectação completa, incompleta ou sem umectação conforme mostra a Figura 2.

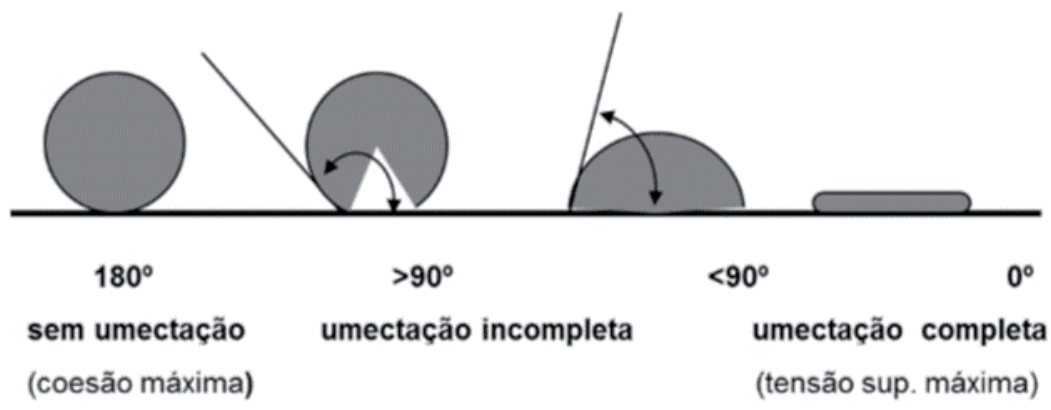

Figura 2 - Ângulo de contato e umectação dos adesivos

Fonte: Iwakiri (2005)

A profundidade de penetração do adesivo no interior do aderente depende da permeabilidade e da porosidade da madeira, da viscosidade, do tempo de cura e da tensão de adesão. A fluidez do adesivo tem importância para que sua penetração ocorra de forma adequada sendo que a falta ou excesso de penetração podem causar linha de cola faminta ou ultrapassagem da linha de cola, respectivamente, colaborando com o enfraquecimento da junta, diminuindo a sua resistência (JESUS, 2000). Segundo Marra (1992 apud IWAKIRI, 2005), o adesivo deve ser aplicado de forma fluida e ancorar na superfície, além de ter boa tensão de adesão e boa tensão de coesão. Para viabilizar tecnicamente e economicamente os produtos colados, as propriedades adesivas desejáveis são a preparação mínima da superfície, custo razoável, fácil aplicação com o mínimo de habilidade, fixação dentro de um tempo razoável e não ter rigidez do adesivo antes de polimerizado. Segundo Mendoza (2010), os principais mecanismos 
para fixação ou cura dos adesivos são a evaporação do solvente, remoção de calor (reativação) e reação química.

No processo de colagem, as seguintes funções de movimento e mobilidade do adesivo são observadas (MARRA, 1992 apud IWAKIRI, 2005):

- A fluidez: que se refere à capacidade que o adesivo possui em escoar ou fluir no plano da superfície do substrato.

- A transferência: que se refere ao movimento de passagem para as duas faces a serem unidas, particularmente nas colagens em que só uma das faces recebe o adesivo.

- A penetração: que corresponde ao movimento do adesivo nas estruturas capilares da madeira.

- O umedecimento: que é o movimento do adesivo no sentido de recobrir a estrutura submicroscópica do substrato, adquirindo maior proximidade e contato em nível molecular.

- A solidificação que se caracteriza por fenômenos envolvidos na mudança do estado físico, incluindo a migração ou evaporação do solvente, orientação molecular, polimerização e "cross-linking".

Os movimentos do adesivo na formação da ligação variam de acordo com sua composição e das condições de colagem. Dependendo da viscosidade do adesivo, a linha de cola formada pode ser classificada em faminta, normal, não-ancorada e pré-endurecida. Ao se utilizar um adesivo de baixa viscosidade, pode ocorrer uma penetração excessiva e o desaparecimento do adesivo através dos poros da madeira, resultando em situação de quantidade insuficiente de adesivo na linha de cola, sendo esta denominada de linha de cola faminta (FRUHWALD, 1977 apud ALMEIDA, 2009). Segundo os mesmos autores, quando é parcialmente polimerizado durante a aplicação da pressão, o adesivo perde a sua mobilidade para "fluir, transferir, penetrar e umectar". Essa situação é conhecida como pré-endurecida. Entre os dois extremos de muito ou pouco movimento, 
se situa a movimentação ótima para cada ação, produzindo uma ligação adequada com a solidificação do adesivo sendo denominada de normal. A condição situada entre a "normal e a "pré-endurecida", em que há suficiente mobilidade para fluidez, alguma transferência e penetração, mas não o suficiente para "umectação", é denominada não ancorada.

Extensores são definidos como substâncias à base de amido e proteína que possuem certa ação adesiva e, quando misturados na composição do adesivo à base de resina uréia-formaldeído, contribuem pra melhorar as características de viscosidade do adesivo. Alguns materiais como, centeio, soja, milho, mandioca, sorgo, aveia, cevada, arroz, caroço de algodão, sangue de animais e batatas têm potencial para serem utilizadas como extensor (MOREIRA, 1984). Segundo Iwakiri et al. (2000), a farinha de trigo é o principal produto utilizado como extensor no Brasil.

Conforme descrito pela $\mathrm{ABIMCI}$ (2003), a utilização de extensores apresenta as seguintes vantagens:

- Menor desgaste das ferramentas de corte.

- Menores custos e plasticidade à linha de cola devido aos extensores.

- Evita tensões interiores que poderiam ocasionar empenamentos.

Porém, apresentam as seguintes desvantagens (ABIMCI, 2003):

- Possibilidade de ataque de microrganismos na linha de cola que contenha farinha como extensor.

- Tempo de cura da cola maior em virtude de excesso de água e farinha.

Iwakiri et al. (2000) mencionam que as principais exigências para um material ser utilizado como extensor são:

- Ser de fácil dispersão em resinas líquidas, resultando numa mistura uniforme e mantendo sua viscosidade durante a aplicação.

- Melhorar a coesividade e capacidade de ligamento do adesivo, aumentando a sua vida útil. 
- Auxiliar no espalhamento, evitando a ultrapassagem do adesivo pela superfície da lâmina externa e derramamento excessivo pelas bordas.

Conforme Mendoza (2010), os aditivos são substâncias químicas que, quando adicionadas ao adesivo, têm a capacidade de melhorar algumas propriedades especificas da peça colada. A autora cita que os aditivos mais utilizados são os catalizadores ou endurecedores, a emulsão de parafina, os retardantes de fogo e os biocidas. O sulfato de amônia e o cloreto de amônia são os principais catalizadores empregados na ureia-formaldeído, pois tornam o meio ácido, o que facilita a cura do adesivo. A emulsão de parafina ajuda a reduzir higroscopicidade da madeira, melhorando assim a estabilidade dimensional da peça. Os retardantes de fogo mais comuns são o fosfato de amônia, o ácido bórico e o bromato de amônia, que, em caso de incêndio, retardam os efeitos do fogo sobre a peça. Os biocidas têm a função de proteger a peça contra ataques de insetos e fungos, sendo os piretroides classificados como inseticidas, e os produtos à base de boro são classificados como fungicida.

\section{CONSIDERAÇÕES FINAIS}

O uso dos adesivos causou uma verdadeira revolução na civilização moderna, mas, infelizmente, o grande problema em relação aos adesivos sintéticos está no tipo de matéria-prima utilizada na sua produção, ou seja, à base de derivados do petróleo. Isso, além de ser ecologicamente incorreto para os padrões sociais atuais, também tem a matéria-prima cada vez mais escassa e cara. Existem muitas pesquisas para substituir os derivados do petróleo, que não são renováveis, por matéria prima renovável, como óleo de mamona, os silicatos e os taninos, oriundos de várias fontes renováveis. Porém, o desafio está em produzir os adesivos naturais em escala industrial, superando suas limitações em relação aos adesivos sintéticos, principalmente no que diz respeito à sua eficiência e custo. 


\section{REFERÊNCIAS}

ASSOCIAÇÃO BRASILEIRA DA INDÚSTRIA DE MADEIRA PROCESSADA MECANICAMENTE (ABIMCI). Artigo técnico no 7. Curitiba, 2003. 6p.

ALMEIDA, N. F.; MORI, F. A.; GOULART, S. L.; MENDES, L. M. Estudo da reatividade de taninos de folhas e cascas de barbatimão Stryphnodendron adstringens (Mart.) Coville. Scientia Forestalis, Piracicaba, SP, v. 38, n. 87, p. 401-408, set. 2010.

ALMEIDA, V. C. Efeito da adição de carga e extensor nas propriedades do adesivo uréia-formaldeído e dos compensados de pinus e paricá. 2009. 75 p. Dissertação (Mestrado em Ciência Florestal)- Universidade Federal de Viçosa, Viçosa, MG, 2009.

AZEVEDO, E. C. Efeito da radiação nas propriedades mecânicas do adesivo de poliuretana derivado do óleo de mamona. 2009. 134p. Tese (Doutorado em Ciência e Engenharia de Materiais) - Universidade Federal do Paraná, Curitiba, PR, 2009.

BIANCHE, J. J. Interface madeira-adesivo e resistência de juntas coladas com diferentes adesivos e gramatura. 2014. 85p. Tese (Doutorado em Ciência Florestal)- Universidade Federal de Viçosa, Viçosa, MG, 2014.

CAMPOS, C. I.; LAHR, F. A. R. Estudo comparativo dos resultados de ensaio de tração perpendicular para MDF produzido em laboratório com fibras de Pinus e de Eucalipto Utilizando Uréia-Formaldeído. Matéria, São Paulo, v. 1, n. 9, p. 32-42, 2004.

CARNEIRO, A. C. O. Efeito da hidrólise ácida e sulfitação de taninos de Eucalyptus grandis W. Hill ex Maiden e Anadenanthera peregrina Speg., nas propriedades dos adesivos. 2006. 182p. Tese (Doutorado em Ciência Florestal)- Universidade Federal de Viçosa, Viçosa, MG, 2006.

CARNEIRO, R. P. Colagem de junta de madeira com adesivo epóxi. 2010. 90p. Dissertação (Mestrado em Engenharia Mecânica) - Universidade Federal do Pará, Instituto de Tecnologia, Belém, PA, 2010.

CARNEIRO, A. C. O.; VITAL, B. R.; CASTRO, A. F. N. M.; SANTOS, R. C.; CASTRO, R. V. O.; PINHEIRO, M.A. Parâmetros cinéticos de adesivos produzidos a partir de taninos de Anadenanthera peregrina e Eucalyptus grandis. Revista Árvore, Viçosa, MG, v. 36, n. 4, p.767- 775, jul./ago. 2012. 
CESAR, A. A. S. Estudo da interação adesivo-partícula em painéis OSB (oriented strand board). 2011. 88p. Dissertação (Mestrado em Ciência e Tecnologia da Madeira)- Universidade Federal de Lavras, Lavras, MG, 2011.

EMERSON, D. W. V. Métodos de análise de formaldeído e otimização da reação de hantzschen. 2010. 91p. Monografia (Graduação em Engenharia Industrial Madeireira)- Universidade Federal do Paraná, Curitiba, PR, 2010. IWAKIRI, S.; CUNHA, A. B.; ALBUQUERQUE, C. E. C.; GORNIAKI, E.; MENDES, L. M. Utilização de extensores alternativos na produção de compensados multilaminados. Ciência Florestal, Santa Maria, RS, v. 10, n. 1, p. 77-83, 2000.

IWAKIRI, S. Painéis de madeira reconstituída. 2. ed. Curitiba: FUPEF, 2005. $254 p$.

JESUS, J. M. H. Estudo do adesivo poliuretano à base de mamona em madeira laminada colada (MLC). 2000. 106p. Tese (Doutorado em Engenharia Civil) - Universidade de São Paulo, São Carlos, SP, 2000.

LIMA, C. K. Avaliação da qualidade de juntas coladas na madeira de clones de Eucalyptus. 2006. 76p. Dissertação (Mestrado em Engenharia Florestal) - Universidade Federal de Lavras, Lavras, MG, 2006.

MACIEL, A. S.; VITAL, B. R.; DELLA LÚCIA, R. M.; PIMENTA, A. S. Painéis de partículas aglomeradas de madeira Pinus elliottii Engelm., poliestireno (PS) e polietileno tereftalato (PET). Revista Árvore, Viçosa, MG, v. 28, n. 2, p. 257-266, mar./abr. 2004.

MENDOZA, Z. M. S. H. Efeito da inclusão laminar nas propriedades de painéis aglomerados fabricados com resíduos da indústria laminadora. 2010. 128p. Tese (Doutorado em Ciência Florestal) - Universidade Federal de Viçosa, MG, 2010.

MOREIRA, W. S. Extensores alternativos para produção de compensados com resina uréia-formaldeído. 1985. 81p. Dissertação (Mestrado em Engenharia Florestal) - Universidade Federal do Paraná, Curitiba, PR, 1985.

RIBEIRO, T. S. Produção de painéis compensados de Pinus taeda com resina uréia-formaldeído utilizando diferentes extensores. 2008. 20p. Monografia (Graduação em Engenharia Florestal) - Universidade Federal Rural do Rio de Janeiro, Seropédica, RJ, 2008. 
STELLA, J. C. A influência de variáveis do ciclo de prensagem e gramatura de cola nas propriedades mecânicas de compensados de paricá (Schizolobium amazonicum). 2009. 51p. Monografia (Graduação em Engenharia Industrial Madeireira)- Universidade Federal do Paraná, Curitiba, PR, 2009.

TEODORO, A. S.; LELIS, R. C. C. Colagem de madeira sólida com adesivo natural à base de tanino. Revista da Universidade Rural: Série Ciências da Vida, Seropédica, RJ, v. 25, n. 1, p. 55-59, jan./jun. 2005.

VITAL, B. R.; MACIEL, A. S.; DELLA LUCIA, R. M. Qualidade de juntas coladas com lâminas de madeiras de três regiões do tronco de Eucalyptus grandis, Eucalyptus saligna e Pinus elliottii. Árvore, Viçosa, MG, v. 30, n. 4, p. 637644, 2006. 